\title{
COMPARAÇÃO ENTRE O SISTEMA PETRIFILM RSA $\AA$ E A METODOLOGIA CONVENCIONAL PARA A ENUMERAÇÃO DE ESTAFILOCOCOS COAGULASE POSITIVA EM ALIMENTOS'
}

\author{
Anderson de Souza SANT"ANA , Denise R. Perdomo AZEREDO
}

\section{RESUMO}

A pesquisa de estafilococos coagulase positiva em alimentos é feita através de sua detecção e enumeração em meios seletivos e diferenciais e posterior caracterização pelos testes de coagulase, termonuclease, Gram e catalase. Estes testes podem requerer até quatro dias para obtenção dos resultados finais, além do tempo e material dispensados ao seu uso. As placas Petrfilm ${ }^{\circledR}$ RSA são uma alternativa a esta metodologia. No presente estudo, foram analisadas 62 amostras de diferentes alimentos comparando-se a metodologia tradicional (ABP), seguido dos testes de coagulaseou Staphytect Plus e o sistema Petrifilm. O sistema Petrifilm ${ }^{\circledR}$ RSA diferiu significativamente da metodologia tradicional, dando médias de contagem superiores. Ao se considerar colônias típicas e atípicas, o ABP seguido de confirmação pelo Staphytect Plus diferiu significativamente dos demais métodos testados. O Petrifilm RSA é uma alternativa para a enumeração de estafilococos coagulase positivos em alimentos, em virtude do menor tempo (aproximadamente 31 horas), para obter-se resultados realmente quantitativos. Deve-se testar tanto colônias típicas quanto atípicas crescidas no ABP, para se evitar falhas na quantificação dos resultados. Esta contagem é mais significativa ao se usar o teste de aglutinação em látex (Staphytect Plus). A análise de estafilococos em alimentos apresenta diversas limitações.

Palavras-chave: Staphylococcus aureus; estafilococos coagulase positiva; teste de coagulase; teste de aglutinação em látex; teste de termonuclease; Petrifilm RSA.

\section{SUMMARY}

COMPARISON OF PETRIFILM RSA SYSTEM WITH THE TRADITIONAL METHODOLOGY FOR THE ENUMERATION OF COAGULASE-POSITIVE Staphylococcus IN FOODS. Foods are examined for the presence of coagulase-positive staphylococci using selective and differential media followed by characterization for coagulase, thermoestable nuclease, Gram and catalase tests. These tests may require up to four days to obtain the results, besides time and material used. The Petrifilm ${ }^{\circledR}$ rapid S.aureus count plate is a alternative to traditional methodology. In this study, 62 samples of several foods were analysed comparing the BPA method followed by coagulase or latex agglutination tests and Petrifilm ${ }^{\circledR}$ RSA method. The Petrifilm ${ }^{\circledR}$ RSA method was significantly different to BPA method, with higher mean log counts. The BPA method followed by latex agglutination test for typical and atypical colonies were significantly different from the other methods used. The Petrifilm ${ }^{\circledR}$ RSA method is an alternative on enumeration of coagulase-positive staphylococci in foods, because true quantitave results were obtained in approximately 31 hours. Typical and atypical colonies on BPA should be tested to obtain accurate results. This count is more significative when latex agglutination test is used. Food analyses for staphylococci showed several limitations.

Keywords: Staphylococcus aureus; coagulase-positive staphylococci; coagulase test; latex agglutination test; termoestable nuclease test; Petrifilm RSA.

\section{1 - INTRODUÇÃO}

As bactérias pertencentes ao gênero Staphylococcus são cocos Gram positivos, imóveis, não esporulados, capsulados ou não, anaeróbios facultativos [5]. O S. aureus produz grande variedade de fatores de patogenicidade $\mathrm{e}$ virulência: estafiloquinases, hialuronidases, fosfatases, coagulases e hemolisinas [7]. A principal fonte do microrganismo é a cavidade nasal, mas pode ser encontrado na pele, mãos, feridas infectadas [3]. Desta forma, o fato de um alimento ser manipulado, já indica uma provável contaminação pelos microrganismos deste gênero. Os animais também são fontes de Staphylococcus, já que algu-

Recebido para publicação em 27/08/2004. Aceito para publicação em 25/07/2005(001396).

Laboratório de Microbiologia de Alimentos e Bebidas. Centro de Tecnologia de Alimentos e Bebidas. SENAI-RJ. Endereço: Rua Nilo Peçanha. 85. Centro. CEP: 27700-000, Vassouras, RJ. Telefone: (24) 24711004. Ramal 233.E-mail: assantana@hotmail.com

CEFET Quimica. Unidade Maracanã/RJ. Endereço: Rua Senador Furtado.121/125.E-mail:denise.perdomo@uol.com.br

A quem a correspondência deve ser enviada. mas espécies podem ser associadas à casos de mastite bovina.

Os estafilococos são causadores de toxinoses alimentares. Estas são produzidas quando há a ingestão de alimento contendo a toxina pré-formada.

A toxina é produzida quando a quantidade de células está entre 10 e $10 \mathrm{UFC} / \mathrm{g}$ ou mL do alimento. Essas toxinas são proteínas de baixo peso molecular (26.00034.000 Da). Hoje são conhecidas onze tipos de enterotoxinas (Staphylococcal enterotoxins SE: A, B, C, C, C, D, $\mathrm{E}, \mathrm{G}, \mathrm{H}, \mathrm{I}$ e J), as quais podem ser diferenciadas por meio de sorologia. As enterotoxinas são altamente termoestáveis $\left(\mathrm{D}_{o, .,}>2\right.$ horas$)$ e resistentes à cocção ou à enzimas proteoliticas. Uma dose de toxina menor que $1,0 \mu \mathrm{g} / \mathrm{Kg}$ (300 a 500ng) em alimentos contaminados produzirá sintomas de toxinose por estafilococos. Esta quantidade de toxina é produzida quando a contagem de células está acima de $10^{5}$ por grama de alimento $[2,7]$.

Tanto espécies coagulase positiva, quanto coagulase negativa são causadoras da toxinose estafilocócica [5]. Já foi relatado surto causado por Staphylococcus epidermidis, uma espécie coagulase negativa [4]. 
A produção de coagulase é muitas vezes associada à capacidade de produção de toxinas por espécies de estafilococos, sendo desta forma um indicador indireto do potencial patogênico do microrganismo, justificando assim seu isolamento $[6,10]$.

S. aureus e $S$. intermedius são produtoras de cogulase livre e ligada (clumping factor) e de termonuclease, enquanto que $S$. hyicus pode ou não ser produtor destas enzimas. [5]. Alimentos normalmente associados a toxinose estafilocócica são leite, carnes, saladas e principalmente produtos bastante manipulados [3].

A pesquisa de estafilococos coagulase positiva em alimentos é feita através de sua detecção e enumeração em meios seletivos e diferenciais e sua posterior caracterização pelos testes de coagulase, termonuclease, coloração de Gram e teste de catalase [6].

O Ágar Baird Parker (ABP) é o meio recomendado pela American Public Health Association (APHA) e Food and Drug Administration (FDA) para o isolamento de $S$. aureus em alimentos. Este meio utiliza a habilidade do $S$. aureus possui se desenvolver na presença de telurito de potássio, glicina, cloreto de lítio e polimixina, que são agentes seletivos. Suas características diferenciais baseiam-se na redução do telurito de potássio à telureto de potássio, produzindo colônias negras e a capacidade de hidrolisar gema do ovo, formando halos ao redor das colônias [11]. O piruvato de sódio é adicionado ao meio de cultura para melhorar a recuperação de células injuriadas, prevenindo o acúmulo de peróxido de hidrogênio, que é tóxico para as células [9]. Posteriormente, as colônias suspeitas típicas devem ser identificadas pelo teste de coagulase em tubos, que detecta a coagulase livre (extracelular) e a ligada, ou em lâminas, que detecta somente a coagulase ligada (clumping factor) [3]. Aproximadamente 97\% das cepas de $S$. aureus de procedência humana possuem ambas as coagulases, a extracelular e a ligada [14].

O teste de termonuclease é tão específico quanto o de coagulase, mas é menos subjetivo, pois envolve a mudança de cor azul para rósea do meio de cultura, não sendo desta forma, um susbtituto do teste de coagulase, mas um teste confirmativo quando coágulos do tipo +2 estão presentes [6].

O teste de aglutinação em látex pode ser usado em substituição ao teste de coagulase se resultados mais rápidos são desejados [6]. Neste teste, há a diferenciação de S.aureus que possuem o clumping factor, a proteína A e o polissacarideo capsular encontrado nas cepas metilicinas resistentes, daqueles que não possuem estas propriedades. S. hyicus e $S$. intermedius também possuem estas propriedades [14]. O reativo de látex é então sensível (forma aglutinação), quando quaisquer das três características estão presentes.

De um modo geral, todos os procedimentos para identificação envolvem uma série de etapas, meios de cultura, reagentes, além de demandarem um tempo maior para obtenção dos resultados finais, o que vai impactar dire- tamente nos custos do laboratório. Desta forma, é crescente a procura por métodos alternativos de análises, que possuam a sensibilidade e especificidade esperados e que melhorem a produtividade laboratorial, reduzindo custos.

As placas Petrifilm ${ }^{\circledR}$ para contagem rápida de $S$. aureus (RSA), são uma alternativa a metodologia tradicional para pesquisa de estafilococos em alimentos.

As placas Petrifilm ${ }^{\circledR}$ RSA são um sistema pronto de meio de cultura que consiste de uma placa Petrifilm que contém os nutrientes de Baird-Parker modificados e um agente gelificante solúvel em água fria, e o disco reativo Petrifilm de nuclease termoestável (disco reativo de termonuclease-Tnase) que contém DNA, azul de o-toluidina e um indicador de tetrazólio para facilitar a enumeração das colônias e a confirmação da presença de nuclease estafilocócica termoestável [15]. Neste teste, tanto S.aureus, S.intermedius e $S$. hyicus produzirão as reações características, pois tais espécies são produtoras de termonuclease [13].

Portanto, o presente trabalho teve por objetivos:

- Comparar o sistema Petrifilm ${ }^{\circledR}$ RSA com o Ágar Baird-Parker para enumeração de estafilococos coagulase positiva em alimentos;

- Comparar os testes de coagulase em tubos e de aglutinação em látex para confirmação de colônias típicas e atípicas de estafilococos coagulase positiva em alimentos;

- Verificar a ocorrência de colônias atípicas de estafilococos coagulase positiva em alimentos e a importância de sua enumeração como fator limitante das metodologias para sua detecção nos alimentos.

\section{2 - MATERIAL E MÉTODOS}

\section{1 - Material}

\subsection{1 - Preparo das amostras}

Foram analisadas 62 amostras de diferentes alimentos, obtidas do comércio da cidade de Vassouras, RJ, entre os meses de maio a dezembro de 2001 e janeiro e fevereiro de 2002. As amostras constituíram-se de: queijos $(n=11)$, iogurte $(n=2)$, gelados comestiveis $(n=2)$, leite pasteurizado $(n=4)$, leite em pó $(n=5)$, pão de queijo congelado $(n=8)$, lingüiça suína $(n=6)$, carnes salgadas $(n=13)$, hambúrguer $(n=6)$, manteiga $(n=2)$, pescado salgado $(\mathrm{n}=2)$.

As amostras foram analisadas de acordo com a metodologia proposta pela American Public Health Association [12].

Adicionou-se $10 \mathrm{~g}$ de amostra assepticamente a $90 \mathrm{~mL}$ de água peptonada $0,1 \%$, seguindo-se a homogeneização em aparelho tipo Stomacher. Diluições seriadas foram feitas adicionando-se $1 \mathrm{~mL}$ da diluição anterior para tubos com $9 \mathrm{~mL}$ de água peptonada $0,1 \%$ estéril. 


\section{2 - Métodos}

\subsection{1 - Método tradicional (Ágar Baird-Parker)}

Placas em duplicata de ABP foram inoculadas com $0,1 \mathrm{~mL}$ de cada diluição. Quando se esperavam contagens menores que $100 / \mathrm{g}$ ou $\mathrm{mL}$ de amostra, inoculou-se $1,0 \mathrm{~mL}$ da diluição 10 divididos em porções de $0,3 \mathrm{~mL}$; $0,3 \mathrm{~mL}$ e $0,4 \mathrm{~mL}$, em três placas de ABP pela técnica do espalhamento.

As placas foram incubadas a $35-37^{\circ} \mathrm{C} / 48 \mathrm{~h}$ e após esse periodo, as colônias presuntivas típicas e atípicas de estafilococos coagulase positiva foram contadas, considerando-se como típicas, aquelas circulares, lisas, convexas, $2-3 \mathrm{~mm}$ de diâmetro, negras com textura úmida, bordas esbranquiçadas e rodeadas por uma zona opaca e freqüentemente com um halo transparente e como colônias atipicas, aquelas negras ou acinzentadas com um ou dois halos e também aquelas sem os halos.

De três a cinco colônias típicas e atípicas de estafilococos coagulase positiva por placa foram selecionadas e transferidas para tubos contendo Ágar TSA (Tryptic Soy Ágar) e incubados a $35-37^{\circ} \mathrm{C} / 24 \mathrm{~h}$. Após esse periodo, as culturas foram repicadas para caldo BHI (Brain Heart Infusion) e incubadas a $35-37^{\circ} \mathrm{C} / 24 \mathrm{~h}$. A partir dos tubos de caldo BHI, foi realizado o teste de coagulase e a partir dos tubos de ágar TSA, foram realizados os testes de Gram, aglutinação em látex e catalase.

Para o teste de coagulase, $0,1 \mathrm{~mL}$ da cultura em caldo $\mathrm{BHI}$ foi adicionado a um tubo contendo $0,3 \mathrm{~mL}$ de plasma de coelho com EDTA reidratado. Seguiu-se a incubação a $35-37^{\circ} \mathrm{C}$ e observação da formação dos coágulos por $6 \mathrm{~h}$. Foram considerados positivos os coágulos $+3 \mathrm{e}+4$.

Para o teste de aglutinação em látex (Staphytect Plus), uma alçada carregada da cultura obtida em ágar TSA foi misturada ao reagente de látex contido no cartão de reação e também submetidas ao teste com o reativo controle. Foram consideradas positivas, as colônias que produziram aglutinação no reagente de látex em até vinte segundos. Aquelas que produziram aglutinação com o reagente controle, foram consideradas culturas autoaglutinantes e os resultados considerados ininterpretáveis.

O número de UFC/g ou mL foi calculado em função do número de colônias típicas e/ou atípicas obtidas, fator de diluição e porcentagem de colônias confirmadas.

\subsection{2 - Petrifilm ${ }^{\circledR}$ para contagem rápida de $S$. au-} reus (RSA)

As placas em duplicata de Petrifilm ${ }^{\circledR}$ RSA foram inoculadas com 1,0mL das diluições usadas para inoculação do método tradicional, foram então, incubadas a 35$37^{\circ} \mathrm{C} / 24 \mathrm{~h}$ e posteriormente transferidas para uma estufa a $62^{\circ} \mathrm{C} \pm 2{ }^{\circ} \mathrm{C}$ e mantidas por $1-4 \mathrm{~h}$. Após, os discos reativos de termonuclease foram colocados nas placas e estas foram incubadas a $35-37^{\circ} \mathrm{C} / 1-3 \mathrm{~h}$.
Após o período de incubação, procedeu-se a contagem, considerando-se colônias vermelhas ou azuis rodeadas por uma área rosada como positivas para estafilococos.

\subsection{3 - Análise estatística}

As amostras foram divididas em dois grupos: leite e derivados (queijos, iogurte, gelados comestiveis, leite pasteurizado, leite em pó, manteiga e pão de queijo congelado) e carnes e derivados (lingüiça suína, carnes salgadas hambúrguer e pescado salgado). Os resultados das contagens foram expressos através do logaritmo decimal do número de colônias por g ou $\mathrm{mL}$ de amostra.

Usou-se a análise de variância e o teste de médias (Teste de Tukey), para avaliar as diferenças significativas entre os seguintes tratamentos:

a) Petrifilm ${ }^{\circledR}$ RSA x ABP + coagulase (colônias típicas) $x$ $\mathrm{ABP}+$ Staphytect Plus (colônias típicas);

b) $\mathrm{ABP}+$ coagulase (colônias típicas) $\mathrm{x} \mathrm{ABP}+$ Staphytect Plus (colônias típicas) x ABP + coagulase (colônias típícas + atípicas) x ABP + Staphytect Plus (colônias típicas + atípicas).

\section{3 - RESULTADOS E DISCUSSÃO}

Os resultados da análise de variância e teste de Tukey para os tratamentos "a" e "b" encontram-se nas Tabelas 1 e 2 .

Todas as colônias típicas ou atipicas isoladas utilizando-se a metodologia tradicional apresentaram-se como cocos, Gram positivos e catalase positiva. NASCIMENTO, CORBIA \& NASCIMENTO [13] constataram a importância da coloração de Gram como forma de eliminar resultados falsos positivos, pois observaram que algumas leveduras podem produzir no ágar Baird Parker, colônias características de S.aureus, podendo ser confundidas com relação à coloração e formação de halo.

A Tabela 1 refere-se à comparação entre o Petrifilm RSA e o ágar Baird Parker, seguido de confirmação das colônias típicas pelo teste de coagulase e também pelo Staphytect Plus. O Petrifilm ${ }^{\circledR}$ RSA apresentou diferença significativa em relação ao ABP seguido de confirmação pelo teste de coagulase e Staphytect Plus para os dois grupos de alimentos.

TABELA 1 - Comparação entre os resultados das contagens de estafilococos coagulase positiva fornecidos por três métodos distintos, através do Teste de Tukey em nivel de 5\% de probabilidade considerando-se somente colônias tipicas.

\begin{tabular}{|c|c|c|c|}
\hline $\begin{array}{c}\text { Grupos } \\
\text { de } \\
\text { Amostras }\end{array}$ & Métodos & $\begin{array}{c}\text { Contagem } \\
(\log \mathrm{UFC} / \mathrm{g} \text { ou } \mathrm{mL})\end{array}$ & $\begin{array}{l}\text { Resultado do } \\
\text { Teste de Tukey }\end{array}$ \\
\hline Leite $\mathrm{e}$ & Petrifilm ${ }^{*}$ RSA & 2,32 & $A^{(1)}$ \\
\hline \multirow[t]{2}{*}{ Derivados } & ABP + coagulase* & 2,10 & B \\
\hline & ABP + Staphytect Plus ${ }^{*}$ & 2,15 & B \\
\hline Carnes e & Petrifilm* RSA & 2,69 & $A(1)$ \\
\hline \multirow[t]{2}{*}{ Derivados } & ABP + coagulase* & 2,36 & B \\
\hline & ABP + Staphytect Plus* & 2,58 & B \\
\hline
\end{tabular}


TABELA 2 - Comparação entre os resultados das contagens de estafilococos coagulase positivos fornecidos por dois métodos distintos considerando-se colônias típicas e colônias típicas + atipicas, através do Teste de Tukey em nivel de 5\% de probabilidade

\begin{tabular}{|c|c|c|c|}
\hline $\begin{array}{c}\text { Grupos } \\
\text { de } \\
\text { Amostras }\end{array}$ & Métodos & $\begin{array}{c}\text { Contagem } \\
(\log \mathrm{UFC} / \mathrm{g} \text { ou } \mathrm{mL})\end{array}$ & $\begin{array}{l}\text { Resultado do } \\
\text { Teste de Tukey }\end{array}$ \\
\hline Leite $\mathrm{e}$ & ABP + Coagulase* & 2,10 & $\mathrm{~B}^{(1)}$ \\
\hline \multirow[t]{4}{*}{ Derivados } & ABP + Staphytect Plus ${ }^{*}$ & 2,15 & B \\
\hline & $\mathrm{ABP}+$ Coagulase $^{* *}$ & 2,40 & B \\
\hline & ABP + Staphytect & 3,20 & A \\
\hline & Plus ${ }^{* *}$ & & \\
\hline Carnes e & $\mathrm{ABP}+$ Coagulase $^{*}$ & 2,36 & $\mathrm{~B}(1)$ \\
\hline \multirow{3}{*}{ Derivados } & ABP + Staphytect Plus ${ }^{*}$ & 2,58 & B \\
\hline & $\mathrm{ABP}+$ Coagulase $^{* *}$ & 2,35 & B \\
\hline & $\begin{array}{l}\text { ABP + Staphytect } \\
\text { Plus } * *\end{array}$ & 3,84 & A \\
\hline
\end{tabular}

ABP seguido de confirmação com coagulase e ABP seguido de confirmação com Staphytect Plus não apresentaram diferença significativa entre si para os dois grupos de alimentos.

Nenhuma das colônias testadas no Staphytect Plus apresentou reação de autoaglutinação. Para os dois grupos de amostras, as médias das contagens com o sistema Petrifilm RSA, foram superiores em relação aos demais métodos. MACH, LINDBERG \& LUND [12], comparando o sistema Petrifilm RSA e o ABP seguido de confirmação com o teste de coagulase, observaram que a média de contagem (log UFC/g), foi maior no primeiro em comparação com o segundo para carne fresca e batatas congeladas. Em seu estudo, utilizaram 219 cepas bacterianas, os autores demonstraram que o Petrifilm ${ }^{\circledR}$ RSA apresentou maior sensibilidade que o método tradicional (ABP + coagulase), sendo a especificidade entre ambos similar. A contagem de colônias de 71 culturas puras, 61 amostras de alimentos naturalmente contaminados e mais que 750 alimentos artificialmente contaminados mostraram que o Petrilfim ${ }^{\circledR}$ RSA foi tão efetivo quanto o método tradicional para enumeração e identificação de S. aureus.

A Tabela 2 refere-se à comparação do ABP, seguido de confirmação dos isolados pelos testes de coagulase e Staphytect Plus, considerando-se somente colônias típicas e também se considerando conjuntamente colônias típicas e atipicas.

Ao se considerar somente colônias típicas, não foi observada diferença significativa entre os testes de coagulase e Staphytect Plus. Diferença significativa foi observada ao se considerar na contagem as colônias típicas e atípicas. Neste caso, o ABP seguido de confirmação das colônias pelo Staphytect Plus diferiu significativamente dos demais métodos.

Estes resultados corroboram ao estudo realizado por NASCIMENTO, CORBIA \& NASCIMENTO [13], os quais relatam a importância de se fazer uma amostragem das placas, tipos de colônias diferentes, sob pena de obter-se falhas na quantificação dessas bactérias, já que foram observadas colônias com ou sem halos e que posteriormen- te, foram confirmadas como $S$. aureus.

Os halos ao redor das colônias de estafilococos coagulase positivos podem algumas vezes não ser observados, em virtude da presença de cepas não lipolíticas. Nem todas as cepas de $S$.aureus têm a capacidade de hidrolisar a gema do ovo $[1,10]$. Cepas isoladas de alimentos desidratados ou congelados, que foram estocados por longos períodos, freqüentemente desenvolvem uma coloração menos negra que as colônias típicas e podem ter aparência rugosa e textura seca [6]. Desta forma, enfatiza-se mais uma vez a importância de se fazer amostragem de colônias típicas e atipicas para posterior confirmação das colônias de estafilococos coagulase positiva. A diferença entre o Staphytect Plus e o teste de coagulase, pode ser explicada pelo fato do primeiro, detectar cepas que possuem a coagulase ligada, a extracelular, proteína A e o polissacarídeo capsular, enquanto o teste de coagulase emtubos detecta somente os dois tipos de coagulase.

O teste de coagulase é considerado o mais simples para diferenciar $S$. aureus potencialmente patogênicos, todavia, nem todas as cepas coagulase positiva produzem toxinas, além do fato de cepas coagulase negativa já terem sido implicadas em surtos [13].

O Petrifilm ${ }^{\circledR}$ RSA dá resultados na metade do tempo necessário quando comparado à metodologia convencional (aproximadamente 78h, considerando-se até a confirmação pelo teste de coagulase). Apresenta como vantagens adicionais: conveniência, redução de espaço para armazenamento de meios prontos, preparação, lavagem e descarte de materiais, melhorando a produtividade laboratorial. MACH, LINDBERG \& LUND [12] descrevem uma outra vantagem, que é o fato deste sistema ser verdadeiramente quantitativo, pois cada colônia é testada para a produção de termonuclease, o que não ocorre com o teste de coagulase que é semiquantitativo, já que colônias características são selecionadas para a confirmação. Os autores afirmam que além de $S$. aureus, S. hyicus e $S$. intermedius, também podem produzir termonuclease (Tnase), dando resultados positivos (colônias azuis ou vermelhas com halo róseo) no Petrifilm ${ }^{\circledR}$ RSA. Tal fato não deve ser visto como um ponto negativo do método e sim como positivo, em virtude destas espécies pertencerem ao grupo dos estafilococos coagulase positiva, os mais envolvidos em surtos de toxinose estafilocócica.

Neste estudo, principalmente para amostras de queijos e lingüiças, a contagem de estafilococos no ABP não foi algumas vezes possivel, em virtude da alta contagem de Micrococcus, mas no sistema Petrifilm RSA estas contagens foram obtidas. Esta diferença pode indicar uma baixa seletividade do ABP frente a microbiota acompanhante que ao se multiplicar impediu o crescimento dos estafilococos coagulase positiva.

INGHAM \& SCHOELLER [8] afirmam que, apesar da metodologia convencional ser amplamente aceita, a enumeração de estafilococos coagulase positiva apresenta al- 
guns inconvenientes, como a baixa especificidade do meio, em face à presença de numerosa microbiota acompanhante e o tempo utilizado na análise, que pode chegar a seis dias até se obter o diagnóstico final.

O Petrifilm ${ }^{\circledR}$ RSA, mostrou-se mais seletivo e menos subjetivo que a metodologia tradicional, não sendo observadas quaisquer reações que pudessem ser confundidas com colônias de estafilococos coagulase positiva.

Dentre as desvantagens observadas ao se usar o Petrifilm ${ }^{\circledR}$ RSA citam-se: i) a etapa de inativação de nucleases termolábeis, pode matar células de estafilococos e tornar testes posteriores destes isolados impossiveis [8]; ii) a necessidade de uma estufa regulada a $62^{\circ} \mathrm{C}$ para a etapa de inativação das nucleases termolábeis, já que esta temperatura de incubação não é usual em laboratórios de microbiologia de alimentos.

\section{4 - CONCLUSÕES}

Os resultados do presente trabalho permitem concluir que:

- $\quad$ o sistema Petrifilm ${ }^{\circledR}$ RSA é uma alternativa viável para a enumaração de estafilococos coagulase positiva em alimentos, em virtude do menor tempo (aproximadamente 31 horas) para a obtenção de resultados quantitativos;

- deve-se considerar e testar tanto colônias típicas quanto atipicas de estafilococos coagulase positivos, sob pena de haverem falhas na sua quantificação. Esta contagem é mais significativa ao se usar o teste de aglutinação em látex (Staphytect Plus);

- a análise de estafilococos coagulase positivos em alimentos apresenta limitações, como a baixa especificidade do meio e o tempo utilizado na análise.

\section{5 - REFERÊNCIAS BIBLIOGRÁFICAS}

[1] BAIRD-PARKER, A.C. The Staphylococci: an introduction. J. Appl. Bacteriol.. Supplement, Oxford, p.1S-8S, 1990.

[2] BALABAN, N. \& RASOOLY, A. Staphylococcal enterotoxins. Int. J. Food Microbiol., v. 61, n.1, p. 1-10, 2000 .

[3] BANWART, G.J. Basic Food Microbiology. $3^{\circ}$ edição. Westport: AVI, 1983.
[4] BAUTISTA, L. \& TAYA, P. A quantitative study of enterotoxin production by sheep milk Staphylococci. Appl. Environ. Microbiol.v. 54, n. 2, p. 566-569, 1988.

[5] DOYLE, M.P. Foodborne bacterial pathogens. New York: MARCEL DEKKER, 1989.

[6] FDA - FOOD AND DRUG ADMINISTRATION. Center for Food Safety and Applied Nutrition. BENNETT, R.W.; LANCETTE, G.A. Staphylococcus aureus. In: Bacteriological and Analytical Manual Online. USA. 2001.Disponível em:

<http:://www.cfsan.fda.gov/ ebam/bam-12html>. Acesso em: 16 mar. 2003.

[7] FORSYTHE, S.J. Microbiologia da Segurança Alimentar, Porto Alegre: ARTMED, 2002.

[8] INGHAM, S.C. \& SCHOELLER, N.P. Comparison of the Baird-Parker agar and 3M Petrifilm rapid S.aureus count plate methods for detection and enumeration of Staphylococcus aureus. Food Microbiol., v. 18, p. 581$587,2001$.

[9] JACKSON, H. \& WOODBINE, M. The effect of sublethal heat treatment on the growth of S.aureus. J. Appl. Environ. Bacteriol. n. 26, p.152. 1963.

[10] LANCETTE, G.A. \& TANINI, S.R. Staphylococcus aureus. In: VANDERZANT, C. \& SPLITTSTOESSER, D.F. (Ed.) Compendium of methods for the microbiological examination of foods. 3 ed. Washington D.C.: AMERICAN PUBLIC HEALTH PRESS. 1992. p.533-550.

[11] LANCETTE, G.A. \& BENNET, R.W. Staphylococcus aureus and Staphylococcal enterotoxins. In: DOWNES, F.P. \& ITO, K. (Ed.) Compendium of methods for the microbiological examination of foods. 4 ed. Washington D.C.: SHERIDAN, 2001. p.387-404.

[12] MACH, P.A.; LINDBERG, K.G. \& LUND, M.E. Evaluation of a Dry, rehydratable film method for rapid enumeration of Staphylococcus aureus. J. AOAC Int., v. 83, n. 5, p. 1096-1010, 2000.

[13] NASCimento, M.G.F., CORBIA, A.C.G. \& NASCIMENTO, E.R. Limitações da técnica de isolamento e enumeração de Staphylococcus aureus. Rio de Janeiro, 2001, 4p. Comunicado Técnico 45. Embrapa.

[14] OXOID. Staphytect Plus DR 850M. Oxoid Limited. Basingstoke, Hampshire. Guia de Interpretação. s.d.

[15] 3M Microbiology Products. Placa Petrifilm para contagem rápida de S.aureus. Folheto de instrução de uso. USA. 1999. 